\title{
Oral candida infection among HIV patients at Kilimanjaro Christian Medical Centre in northern, Tanzania
}

\author{
GWAKISA NGASALA ${ }^{1}$, MASEKE R. MGABO ${ }^{1,4}$, JOHN G. MREMA ${ }^{3}$, JANET SABUNI ${ }^{2}$, STEVEN MWAKALINGA ${ }^{1}$ \\ and DEBORA C. KAJEGUKA ${ }^{1^{*}}$ \\ ${ }^{1}$ Faculty of Medicine, Kilimanjaro Christian Medical University College, P.O. Box 2240, Moshi, Tanzania \\ ${ }^{2}$ Kilimanjaro Christian Medical Centre, P.O. Box 3010, Moshi, Tanzania \\ ${ }^{3}$ School of Medical Laboratory Training Centre, P.O.Box 5030, Tanga, Tanzania \\ ${ }^{4}$ Institute of Rural Development Planning, P.O.Box 138, Dodoma, Tanzania
}

\begin{abstract}
Background: Oral candidiasis has been a global health challenge especially in immunocompromised patients particularly with HIV infection. Though the incidence and prevalence of opportunistic infections have been reduced due to the use of anti-retroviral therapy (ART), oral candidiasis remains the most frequently HIV-associated oral lesion in Tanzania. This study aimed at determining the prevalence of oral candida infection in HIV positive patients and investigate the relationship between oral manifestations and the level of immunosuppression.

Method: This study was carried out at Kilimanjaro Christian Medical Centre in Moshi, Tanzania. The study included 314 HIV patients with complete clinical results records who were diagnosed with HIV and who were on ARV and attending the hospital for care and treatment.

Results: Prevalence of oral candida was 42.0\% (132/314). Age group 6-27 years accounted for half of the infections (49/98). A significantly higher prevalence of candida infection $(66.7 \% ; 24 / 36)$ was obseved among patients with $<200$ cells $/ \mu$ l than in those with $200-500$ cells $/ \mu$ l or $>500$ cells $/ \mu$ l (Chi-square $\chi^{2}=14.9$, $p=0.001)$. The mean CD4+T-cell counts in HIV patients infected with oral candida was lower (523 \pm 35$)$ than patients without oral candida infection ( $645 \pm 31$ cells $/ \mu$ ), (ANOVA, $p=0.009$ ). The mean CD4+ T-cell count among HIV patients on ART and those not on ART was not statistically different.

Conclusion: The prevalence of oral candida infection was significantly higher in patients with CD4+ cell counts less than 200 cells/ $\mu$ l.

Keywords: Oral, candida, HIV, Tanzania
\end{abstract}

\section{Introduction}

Human immunodeficiency virus (HIV) infection is major global health concerns due to its continued spread in different parts of the world. It has been revealed that candidiasis is a opportunistic infection and commonly occur in patients with HIV infection (Morgan, 2005), and most patients are infected with a strain originally existing as a commensal of the oral cavity (Wabe et al., 2012). The incidence of candida infections in HIV patients has been increasing (Mousavi et al., 2012) and poses a public health concern in Sub Saharan Africa. It has been reported that the rate of disease progression varies significantly among patients and can be indicated by laboratory markers (Patil \& Ganapathy, 2011) and therefore, oral candidiasis has been shown to be an important indicator of increased immunosuppression (Santos et al., 2001;

\footnotetext{
* Correspondence E-mail: dkajeguka@gmail.com
} 
Davoodi et al. 2010; Bodhade et al.2011; Patil \& Ganapathy, 2011). However, in some studies, nonHIV infected and those infected with HIV with higher CD4+ T cell counts have also been found infected with candidiasis (Katz et al., 1992).

Though the incidence and prevalence of opportunistic infection have been reduced worldwide due to use of anti-retroviral therapy (ART) (Diz Dios et al., 2001; Ceballos-Salobrena et al., 2004), oral candidiasis remains the most frequent HIV-associated oral lesion in most developing countries including Tanzania. In Tanzania, oral candidiasis is the common condition in HIV infected patients with prevalence ranging from $20 \%$ to 80 \% (Schiødt et al., 1990; Hamza et al., 2006; Kahabuka et al., 2007; Mwangosi \& Majenge, 2011).

There is no study, which has explored the prevalence of oral candida infection in HIV/AIDS patients in northern Tanzania. Therefore, the objective of the present study was to retrospectively determine the prevalence of oral candida infection and investigate the relationship between oral manifestations and the level of immunosuppression among HIV positive patients attending Kilimanjaro Christian Medical Centre in northern Tanzania.

\section{Material and Methods}

\section{Study area}

This study was conducted at Kilimanjaro Christian Medical Centre (KCMC) in Moshi, Tanzania. KCMC is a consultant referral hospital with 450 inpatient beds serving several regions in northern part of Tanzania.

\section{Study design and data collection}

The study was a descriptive retrospective involved HIV infected patients who received treatment and prescription at Child Centred Family Care Clinic at KCMC for a period of 12 months. A total of 314 files were selected from medical records by using convenient sampling. Patient's files were reviewed for demographic characteristics, ART use and CD4 T-cell counts. The inclusion criteria was HIV positive status and the exclusion criteria was incomplete record of data of patients who received care and treatment and those who were referred at KCMC from other health care facilities.

In all patient files reviewed oral candida were diagnosed clinically. During reviewing process, all patients files with complaints as either or not painful ulcers in the mouth were recored. All files which were recored as painful ulcers in the mouth were further reviewed to identify and record those with whitish patches like unfresh milk.

\section{Data analysis}

Analysis of data was carried out using Statistical Package for Social Sciences (SPSS) version 20.0 (SPSS Inc., Chicago, USA). Descriptive statistics for categorical data were summarised and 
tabulated while for continuous variables such as age, CD4 T-cell count mean values were calculated using $t$-test after checking for the normality. For the categorical outcome variables frequencies and proportions was computed whereas association between categorical variables was computed using Chi-square test. A value $<0.05$ were considered to be statistically significant.

\section{Ethical considerations}

Ethical approval was sought from the Kilimanjaro Christian Medical University College Research and Ethics Review Committee. Permission to conduct the study and review medical records was granted by the Director of Kilimanjaro Christian Medical Centre. Each patient's file was given a study identification number and confidentiality was maintained. No names or any personal information was recorded from the patient files.

\section{Results}

The study included 314 (male=111; females=203) HIV positive patients, the median age of the study participants was 24 years (range $=1-81$ years). Generally, of the 314 HIV positive patients, $42.0 \%$ (132/314) were positive for oral candida infection while 58.0\% (182/314) were negative. Fifty-two (46.8\%) of the males and 80 (39.4\%) of the females had candida infectionn (Table 1). ART usage was $43.7 \%$ (111/254) among patients with candida infection and 56.3\% (143/254) among patients without candida infection. There was no difference in ART usage among patients with or without candida infection. (Chi-square $\chi^{2}=1.50, p=0.21$ ).

Table 1: Demographic characteristic, ART usage and and CD4+T-cel

\begin{tabular}{|c|c|c|c|c|c|}
\hline \multirow[t]{2}{*}{ Variables } & \multirow[t]{2}{*}{ Response } & \multirow[t]{2}{*}{ No. } & \multicolumn{2}{|c|}{ Oral Candida infection } & \multirow[t]{2}{*}{$P$-value } \\
\hline & & & Positive \% (n) & Negative \% (n) & \\
\hline All patients) & & 314 & $42.0(132)$ & $58.0(182)$ & - \\
\hline \multirow[t]{2}{*}{ Sex } & Male & 111 & $46.8(52)$ & $53.2(59)$ & \\
\hline & Female & 203 & $39.4(80)$ & $60.6(123)$ & 0.20 \\
\hline \multirow[t]{2}{*}{ ART use } & Yes & 254 & $43.7(111)$ & $56.3(143)$ & \\
\hline & No & 60 & $35.0(21)$ & $65.0(39)$ & 0.21 \\
\hline \multirow[t]{3}{*}{ Age category (years) } & $1-5$ & 33 & $27 \cdot 3(9)$ & $72.7(24)$ & \\
\hline & $6-17$ & 98 & $50.0(49)$ & $50.0(49)$ & \\
\hline & $\geq 18$ & 183 & $40.4(74)$ & $59.6(109)$ & 0.05 \\
\hline CD4 + T-cell category & $<200$ & 36 & $66.7(24)$ & $33 \cdot 3(12)$ & \\
\hline \multirow{2}{*}{ 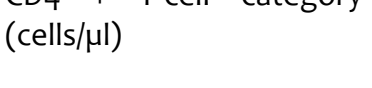 } & $200-500$ & 113 & $45.1(51)$ & $54.9(62)$ & \\
\hline & $>500$ & 165 & $34.5(57)$ & $65.5(108)$ & 0.001 \\
\hline
\end{tabular}

Age group 6-27 years accounted for half (50.0\%; 49/98) of the infections as compared to those within $1-5$ years $27.3 \%$ (9/33) and $\geq 18$ years $40.4 \%$ (74/183), though the association was marginally significant (Chi-square $\chi^{2}=5.69, p=0.05$ ). A significantly higher prevalence of candida infection (66.7\%; 24/36) was obseved among patients with <200 cells/ $\mu$ l followed $45.1 \%$ (51/113) and lastly $34.5 \%$ (57/165) among patients with 200-500 cells/ $\mu \mathrm{l}$ and $>500$ cells $/ \mu l$, repectively (Chi-square 
$\left.\chi^{2}=14.9, p=0.001\right)$.

Table 2: Mean CD+ T-lymphocyte cells among HIV positive patients

\begin{tabular}{lllll}
\hline Variable & Response & No. & CD4+ T- cell (cells/ $\boldsymbol{\mu l})$ Mean \pm SD & P-value \\
\hline Oral Candida Infection & Positive & 132 & $523 \pm 35$ & \\
& Negative & 182 & $645 \pm 31$ & 0.009 \\
Use of ARV & Yes & 254 & $582 \pm 423$ & \\
& No & 60 & $644 \pm 357$ & 0.29 \\
\hline
\end{tabular}

Key: $\mathrm{SD}=$ Standard Deviation, $\mathrm{Cl}=$ Confidence Interval, $\mathrm{ANOVA}=$ Analysis of Variance

The overall $C D 4+T$-cell count mean was $594 \pm 411$. The mean $C D 4+T$-cell counts in HIV patients infected with oral candida was lower $(523 \pm 35)$ than in patients without oral candida infection (645 \pm 31$)$, (ANOVA, $p=0.009$ ). Mean CD4+ T-cell among HIV patients who were on ART and those not on ART was not different (Table 2).

\section{Discussion}

The prevalence of oral candidiasis in our study was lower that that previously reported in Dar es Salaam, Tanzania (Kahabuka et al., 2007) and Nigeria (Esebelahie et al., 2013). However, it was higher than that reported in Uganda (Nanteza et al., 2014). The observed differences in the prevalence are likely to be due to different study designs and population. A study by Kahabuka et al. (2007) employed prospective crossectional design while Nanteza et al. (2014) used consecutively cross sectional design. Both the two studies excluded individuals $\leq 18$ years old (Nanteza et al., 2014; Kahabuka et al., 2007). On the other hand, the study in Nigeria (Esebelahie et al., 2013) compared candida colonization in asymptomatic HIV patients and control.

Although in our study we could not find any difference between the prevalence of candida infection between males and females, s study in India indicated that more males than femaled were infected with oral candida (Ranganathan et al., 2004). In Nigeria, Okonkwo et al. (2013) reported that more females than males are infected with oral candida. We observed that HIV patients with age of 6 to 17 years were more infected by oral candida infection than the other age groups. While there is no clear explaination to this, a previous study in Nigeria reported that adults (2-40 years) are more frequently infected with candida infection than other age groups (Eweka, 2012).

Although there are evidences that the use of ART in HIV patients decrease the prevalence of oral candidiasis (Schmidt-Westhausen et al., 2000; Dunic et al., 2004), our findings indicate that four out ten of the patients on ART were infected. This rate was higher than that previously reported in Dar es Salaam by Hamza et al. (2006). Similar to our findings, a recent study in Nigeria (Esebelahie et al., 2013) reported that $44.0 \%$ of patients who are on ART were infected with oral candida infection. Reason for this high prevalence of oral candida infection among patients on ART is probably due to lack of ART adherence (Owotade et al., 2013; Abebe \& Kassa, 2014). 
Comparing the mean oral candida infection between those on ART and those not on ART, our findings could not establish any association between the two. Similar findings have been reported elsewhere (Costa et al., 2006; Nweze \& Ogbonnaya, 2011; Kwamin et al., 2013).

It has been reported that during the course of HIV infection, the rate of candida infection is inversely associated to the CD4 T-cell counts of the patient (Pappas et al., 2003) and several studies documented that oral candida infected patients have low ( $<200$ cells $/ \mu$ l) $C D 4+T$ cells (Davoodi et al., 2010; Bodhade et al., 2011; Patil \& Ganapathy, 2011). We have noted a significant association between oral candidiasis and CD4+ T-cell count. The prevalence of candida infection was significantly higher in patients with CD4+ cell counts less than 200 cells/ $\mu$ l. This is inline with previous report by Delgado et al. (2009) which showed that CD4+ T-cell counts $<200$ cells/ $\mu$ l were significantly more frequent in patients with oral candidiasis.

The present study used secondary data in which some important variables could have not been documented well. Laboratory results on candida diagnosis were not available during data collection. Also in our study we did not have data for the duration of ART use, which would have given a clear picture in associating occurance of candida infection. Although our study was limited to secondary data and from only one health care facility, we report a high prevalence of oral candida infection among HIV patients in northern Tanzania. We have noted a significant association between oral candidiasis and CD4+ T-cell count.

\section{Acknowledgements}

The authors thank the Kilimanjaro Christian Medical Centre and Child Centered Family Care Clinic. Also authors thank staff from the medical record department for assistance with data acquisition. This study received financial assistance from the Tanzania Loan Board.

\section{Competing Interests}

No competing interest to declare

\section{Authors' contributions}

DCK designed the study, participated in data collection and designed the manuscript. GN participated in data collection, provided critical advice on data analysis and manuscript writing. MRM provided critical advice on data analysis and manuscript writing. JGM and JS reviewed files and participated in designing the manuscript. SM critically reviewed the manuscript. 


\section{References}

Abebe, M. \& Kassa, G. (2014) Prevalence of opportunistic infections and associated factors among hiv positive patients taking anti-retroviral therapy in DebreMarkos Referral Hospital, Northwest Ethiopia. Journal of AIDS \& Clinical Research 5 (5).

Bodhade, A.S., Ganvir, S.M. \& Hazarey, V.K. (2011) Oral Manifestations of HIV infection and their correlation with CD4 count. Journal of Oral Science 53, 203-211.

Ceballos-Salobreña, A., Gaitaín-Cepeda, L., Ceballos-García, L. \& Samaranayake, L.P. (2004) The effect of antiretroviral therapy on the prevalence of HIV-associated oral candidiasis in a Spanish cohort. Oral Surgery, Oral Medicine, Oral Pathology, Oral Radiology, and Endodontics 97, 345-350.

Costa, C.R., Cohen, A.J., Fernandes, O.F.L., Miranda, K.C., Passos, X.S., Souza, L.K.H. \& Silva, M.D.R.R. (2006) Asymptomatic oral carriage of Candida species in HIV-infected patients in the highly active antiretroviral therapy era. Revista do Instituto de Medicina Tropical de São Paulo 48, 257-261.

Davoodi, P., Hamian, M., Nourbaksh, R. \& Ahmadi Motamayel, F. (2010) Oral manifestations related to CD4 lymphocyte count in HIV-positive patients. Journal of Dental Research, Dental Clinics, Dental Prospects 4, 115-9.

Delgado, C.D., de Jesus Pedro, R., Aoki, F.H., Resende, M.R., Trabasso, P., Colombo, A.L., de Oliveira, M.S.M., Mikami, Y. \& Moretti, M.L. (2009) Clinical and microbiological assessment of patients with a long-term diagnosis of human immunodeficiency virus infection and Candida oral colonization. Clinical Microbiology and Infection 15, 364-371.

Diz Dios, P., Ocampo, A., Otero, I., Iglesias, I. \& Martínez, C. (2001) Changes in oropharyngeal colonization and infection by Candida albicans in human immunodeficiency virus-infected patients. Journal of Infectious Diseases 183, 355-356.

Dunic, I., Vesic, S. \& Jevtovic, D.J. (2004). Oral candidiasis and seborrheic dermatitis in HIVinfected patients on highly active antiretroviral therapy. HIV Medicine 5, 50-54.

Esebelahie, N.O., Enweani, I.B. \& Omoregie, R. (2013) Candida colonisation in asymptomatic HIV patients attending a tertiary hospital in Benin City, Nigeria. Libyan Journal of Medicine 8, 20322.

Eweka, O.M. (2012) Prevalence of oral lesions and the effects of HAART in adult HIV patients attending a tertiary hospital in Lagos, Nigeria. Open Journal of Stomatology 2, 200-205.

Hamza, O.J., Matee, M., Simon, E.N.M., Kikwilu, E., Moshi, M.J., Mugusi, F., Mikx, F.H.M., Verweij, P.E. \& van der Ven, A.J.A.M. (2006) Oral manifestations of HIV infection in children and adults receiving highly active anti-retroviral therapy [HAART] in Dar es Salaam, Tanzania. BMC Oral Health 6: 12.

Kahabuka, F., Fabian, F., Petersen, P.E. \& Nguvumali, H. (2007) Awareness of HIV/AIDS and its oral manifestations among people living with HIV in Dar es Salaam, Tanzania. African Journal of 
AIDS Research 6 , 91-95.

Katz, M.H., Greenspan, D., Westenhouse, J., Hessol, N.A., Buchbinder, S.P., Lifson, A.R., Shiboski, S., Osmond, D., Moss, A., Samuel, M. \& et al. (1992) Progression to AIDS in HIV-infected homosexual and bisexual men with hairy leukoplakia and oral candidiasis. AIDS 6, 95-100.

Kwamin, F., Nartey, N.O., Codjoe, F.S. \& Newman, M.J. (2013) Distribution of candida species among HIV-positive patients with oropharyngeal candidiasis in Accra, Ghana. Journal of Infection in Developing Countries 7, 41-45.

Morgan, J. (2005) Global trends in candidemia: review of reports from 1995-2005. Current infectious Disease Reports 7, 429-439.

Mousavi, S.A.A., Salari, S., Rezaie, S., Nejad, N.S., Hadizadeh, S., Kamyabi, H. \& Aghasi, H. (2012) Identification of Candida species isolated from oral colonization in Iranian HIV-Positive Patients, by PCR-RFLP method. Jundishapur Journal of Microbiology 5, 336-340.

Mwangosi, I.E. \& Majenge, J.M. (2011) Prevalence and awareness of oral manifestations among people living with HIV/AIDS attending counselling and treatment centres in Iringa Municipality, Tanzania. Tanzania Journal of Health Research 13, 205-213.

Nanteza, M., Tusiime, J.B., Kalyango, J. \& Kasangaki, A. (2014) Association between oral candidiasis and low CD4+ count among HIV positive patients in Hoima Regional Referral Hospital. BMC Oral Health 14 (1): 143.

Nweze, E.I. \& Ogbonnaya, U.L. (2011). Oral Candida isolates among HIV-infected subjects in Nigeria. Journal of Microbiology, Immunology and Infection 44, 172-177.

Okonkwo, E.., Alo, M.., Nworie, O., Orji, J.. \& Agah, M.. (2013) Prevalence of oral candida albicans infection in HIV sero-positive patients in Abakaliki. American Journal of Life Sciences 1 (2): 72.

Owotade, F.J., Patel, M., Ralephenya, T.R.M.D. \& Vergotine, G. (2013) Oral candida colonization in HIV-positive women: associated factors and changes following antiretroviral therapy. Journal of Medical Microbiology 62, 126-132.

Pappas, P.G., Rex, J.H., Lee, J., Hamill, R.J., Larsen, R.A., Powderly, W., Kauffman, C.A, Hyslop, N., Mangino, J.E., Chapman, S., Horowitz, H.W., Edwards, J.E. \& Dismukes, W.E. (2003). A prospective observational study of candidemia: epidemiology, therapy, and influences on mortality in hospitalized adult and pediatric patients. Clinical Infectious Diseases 37, 634-643.

Patil, B. \& Ganapathy, K. (2011) Correlation of oral manifestations with circulating CD4+ t lymphocytes in patients with HIV/AIDS in Indian Subpopulation. Journal of Indian Academy of Oral Medicine and Radiology 23, 502-506.

Ranganathan, K., Reddy, B.V, Kumarasamy, N., Solomon, S., Viswanathan, R. \& Johnson, N.W. (2004) Oral lesions and conditions associated with human immunodeficiency virus infection in 300 south Indian patients. Oral Diseases $6,152-157$.

Santos, L.C., Castro, G.F., de Souza, I.P. \& Oliveira, R.H. (2001) Oral manifestations related to immunosuppression degree in HIV-positive children. Brazilian Dental Journal 12, 135-138.

Schiødt, M., Bakilana, P.B., Hiza, J.F., Shao, J.F., Bygbjerg, I.B., Mbaga, I., Vestergaard, B.F., 
Nielsen, C.M., Lauritzen, E. \& Lerche, B. (1990) Oral candidiasis and hairy leukoplakia correlate with HIV infection in Tanzania. Oral Surgery, Oral Medicine, and Oral Pathology 69, 591-596.

Schmidt-Westhausen, a M., Priepke, F., Bergmann, F.J. \& Reichart, P.A (2000) Decline in the rate of oral opportunistic infections following introduction of highly active antiretroviral therapy. Journal of Oral Pathology \& Medicine 29, 336-341.

Wabe, N., Hussein, J., Suleman, S. \& Abdella, K. (2012) In vitro antifungal susceptibility of Candida albicans isolates from oral cavities of patients infected with human immunodeficiency virus in Ethiopia. In: 17th International Symposium on HIV and Emerging Infectious Diseases (ISHEID) Marseille, France. 23-25 May 2012. Available from: http://www.retrovirology.com/content/9/S1/P44. 